\title{
Assessment of the flow behavior and structural performance of open-cell aluminum foams at critical flow conditions of pressure and temperature
}

\author{
Manuel F. Azamar ${ }^{1, a)}$, Ignacio A. Figueroa ${ }^{1, a)}$, Gonzalo González ${ }^{1}$, Ismeli Alfonso ${ }^{2}$ \\ ${ }^{1}$ Instituto de Investigaciones en Materiales, Universidad Nacional Autónoma de México, Ciudad Universitaria, Coyoacán, 04510 Ciudad de México, \\ Mexico \\ ${ }^{2}$ Instituto de Investigaciones en Materiales, Unidad Morelia, Universidad Nacional Autónoma de México, Campus Morelia, 58190 Morelia, \\ Michoacán, Mexico \\ a) Address all correspondence to these authors.e-mails: manuel.azamar.j@comunidad.unam.mx; iafigueroa@unam.mx \\ Received: 29 May 2021; accepted: 8 September 2021; published online: 12 October 2021
}

Open-cell Al foams were produced by the replication casting technique in three different pore sizes. All produced foams were physically characterized, determining their relative density, porosity, and pores per inch, as well as their mean pore surface area and diameter. Permeability tests were carried out by means of the injection of a highly pressurized gasoline additive at room temperature and $200{ }^{\circ} \mathrm{C}$, at pressures of up to $25,000 \mathrm{psi}$. The structural capacity of the studied specimens to conduct fluids at these critical experimental conditions was assessed by means of compression tests in order to determine their mechanical properties after the permeability tests, e.g., energy absorption capacity, Young's modulus, and plateau stress. It was found that the produced open-cell Al foams were able of conducting the gasoline additive at critical flow conditions of pressure and temperature, without suffering important physical nor structural damage.

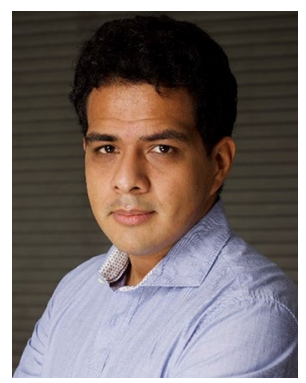

Manuel F. Azamar

Manuel F. Azamar has been in the Department of Advanced Metallic Materials of the Institute for Materials Research at National Autonomous University of Mexico as Research Fellow since September 2019. He received his B.S.E. in Mechanical Engineering from Veracruz Institute of Technology and his Ph.D. in Materials Science and Engineering in the Institute for Materials Research at National Autonomous University of Mexico. After graduate school, he worked for a year as a Jr. Researcher in the Welding and Metallurgy Department of the Research and Development Center of Tenaris TAMSA (Tubos de Acero de México, S.A.), developing and designing welding technologies for pipelines, widely used for the extraction and conduction of oil ashore and offshore. Azamar's interests include the fabrication and characterization of metallic foams. He is particularly focused on the hydraulic and mechanical characterization of open-cell metallic foams, as well as the microstructural features associated. He is also interested in aluminum and magnesium foams for energy absorption for military applications.

\section{Introduction}

A metallic foam is a porous material consisting of a solid metal matrix with fluid-filled or unfilled pores or cells distributed throughout its structure. According to the physical pore-pore interconnection, these can be open or closed cell $[1,2]$. Depending on the desired structural and mechanical properties, there are different methods for metallic foam fabrication. Some of them are metal deposition [2], the powder metallurgy method $[3,4]$, and the liquid-state processes, i.e., the replication casting technique and the foaming by blowing agent [5-9]. Recently, an unconventional technique to produce metallic foams without foaming agents or space holders has been reported. This method 
consists of the formation of an icosahedral-quasicrystalline phase in the $\mathrm{Al}-\mathrm{Fe}-\mathrm{Cu}$ system [10-12].

Nowadays, open-cell $\mathrm{Al}$ foams are in increasing demand. Owing to the properties offered by $\mathrm{Al}$ as base metal, in addition to their porous interconnected structure, open-cell $\mathrm{Al}$ foams can be tailored in a wide range of applications, e.g., lightweight materials with high stiffness [3], metallic foam panels for sound and energy absorption [3], in vibration damping and electromagnetic shielding [13], as well as in heat exchangers, filters, catalyst carriers, and electrodes in aluminum-air batteries, where the combination of thermal/electrical conductivity and liquid/gas permeability is needed [14]. The functionality and possible uses of open-cell $\mathrm{Al}$ foams are strongly associated with their pores' shape, size, distribution, and physical interconnection. Thus, while specimens with larger pores have a higher strength and stiffness due to their thicker struts [15], foams with smaller pores are better for electrical conductivity because of their larger effective surface $[7,16]$. In fluid conduction applications, where the pass through the cellular metal of a liquid or gaseous medium might be required, there may be a need for various degrees of "openness", ranging from "very open" for high-rate fluid flow to "completely closed" for load-bearing structural applications [16]. In addition, open-cell Al foams offer the chance of transporting the fluid, while this is cooled down or heated on its path. Therefore, special attention has been paid on the permeability and fluid flow behavior through open-cell Al foams.

Permeability tests essentially consist of the controlled injection of a given fluid through the interconnected porosity of a porous material, measuring the drop of pressure and the flowrate related to the configuration of the sample's internal morphology. The use of open-cell Al foams in fluid flow applications requires a thorough understanding of the drop of pressure behavior of the fluid flowing through the porous structure [17]. Despois and Mortensen [18] studied the permeability of microcellular aluminum produced in cell sizes of 75 and $400 \mu \mathrm{m}$ and relative densities between 12 to $32 \%$, using water and glycerine as testing fluids. Boomsma and Poulikakos [17] investigated the experimental hydraulic characteristics and form coefficient of open-cell $\mathrm{Al}$ foams of various porosities and pore diameters in both compressed and uncompressed form, using water as testing fluid. Fernández-Morales et al. [19] determined the coefficients of permeability and thermal conductivity of aluminum metal foam, using water as testing fluid. Dukhan [20] analyzed the flow behavior of metal foams, emphasizing on the influence of parameters such as Reynolds and Darcy number on the friction factor, pressure drop, and velocity of air flowing through the foams. Otaru et al. [21] measured and simulated the pressure drop across replicated porous aluminum in the Darcy-Forchheimer regime. Mancin et al. [22] analyzed experimentally and theoretically the pressure losses during airflow in aluminum foams with different physical properties. In summary, the drop of pressure behavior and flow behavior of open-cell $\mathrm{Al}$ foams have been previously investigated, conducting permeability tests within different considerations of testing fluid, flowrate, velocity, and cell/pore sizes. Nonetheless, the range of experimental conditions has been limited, i.e., variables such as injection/flow pressure and testing temperature, as these variables restrict the functionality of $\mathrm{Al}$ foams for potential applications. Permeability tests reported in the literature exceed neither a pressure of 500 psi nor a testing temperature higher than room temperature. Moreover, any possible structural damage caused to the tested samples, because of the testing conditions, has been ignored.

This work analyzes the flow behavior when one single-phase fluid is injected through open-cell $\mathrm{Al}$ foams, reaching pressure values up to 25,000 psi. Permeability tests were conducted at room temperature and $200{ }^{\circ} \mathrm{C}$, with the aim of observing the effect of temperature on the flow and drop of pressure behaviors for possible applications in oil/gas extraction and conduction, as well as to assess the foams' structural performance at critical fluid flow conditions for general application in fluids conduction. The mechanical properties of the $\mathrm{Al}$ foams after permeability tests were determined by means of uniaxial compression tests and then compared using Gibson-Ashby model. Moreover, the fracture behavior of foams after compression tests was assessed using high-resolution pictures.

\section{Results and discussion}

\section{Foams structure}

Representative cylinder samples of the produced open-cell $\mathrm{Al}$ foams with different pore sizes are shown in Fig. 1. The resulting size difference among pores A (Fig. 1a), B (Fig. 1b), and C (Fig. 1c) is reasonably significant, as expected. From the longitudinal section of these cylinders (Fig. 1d-f), it can be noticed that the foams did not present defects linked to their fabrication process, such as lack of infiltration or $\mathrm{NaCl}$ particles embedded. It is also observed that the geometry of the pore is highly irregular, resulting from the used $\mathrm{NaCl}$ particles. The corresponding SEM micrographs of the open-cell $\mathrm{Al}$ foams are shown in Fig. 2a-c, where the interconnecting windows (bottlenecks) can be appreciated, thereby demonstrating that all samples had open-cell structures with interconnected porosity. The determination of dimensional properties related to the bottlenecks was avoided, as they would not be representative due to the irregular shape of the pores.

Results of physical characterization are compiled in Table 1. From this table, it can be noted that the density, relative density, and the effective porosity were not correlated with the pore size, as all analyzed samples had a similar magnitude of these 
(a)

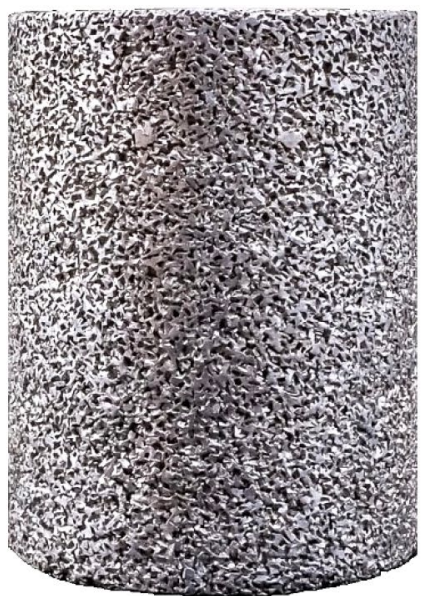

(d)

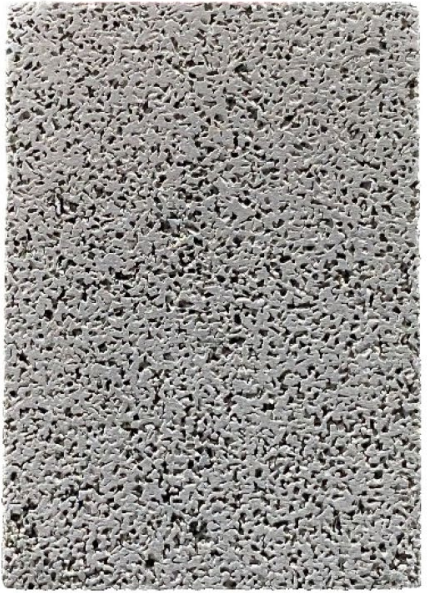

(b)

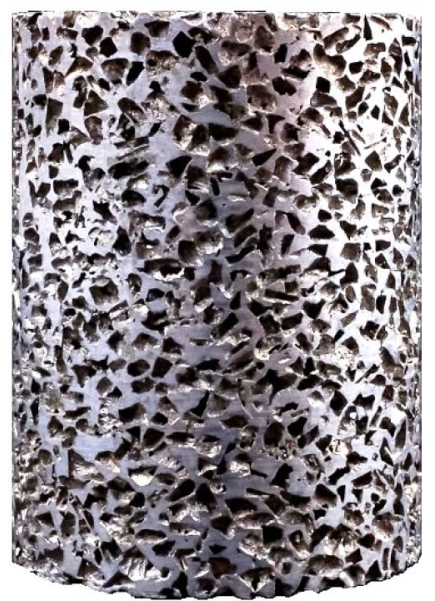

(e)

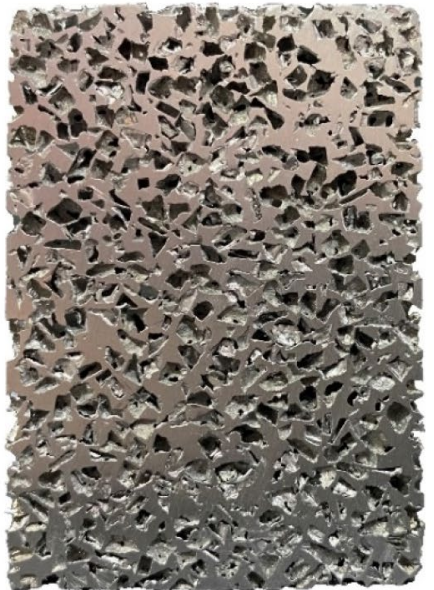

(c)

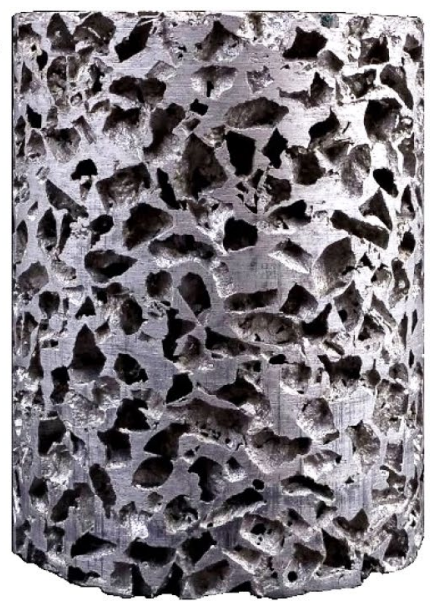

\section{$1 \mathrm{~cm}$}

(f)

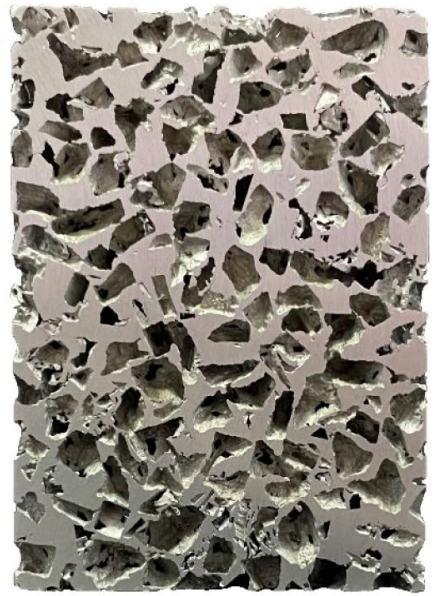

Figure 1: Al foams produced with pore sizes of (a) 0.71 to $1.00 \mathrm{~mm}$, (b) 2.00 to $2.38 \mathrm{~mm}$, and (c) 3.35 to $4.75 \mathrm{~mm}$. Longitudinal section of the foams with pores, (d) 0.71 to $1.00 \mathrm{~mm}$, (e) 2.00 to $2.38 \mathrm{~mm}$, and (f) 3.35 to $4.75 \mathrm{~mm}$. The scale bar is the same for all images.
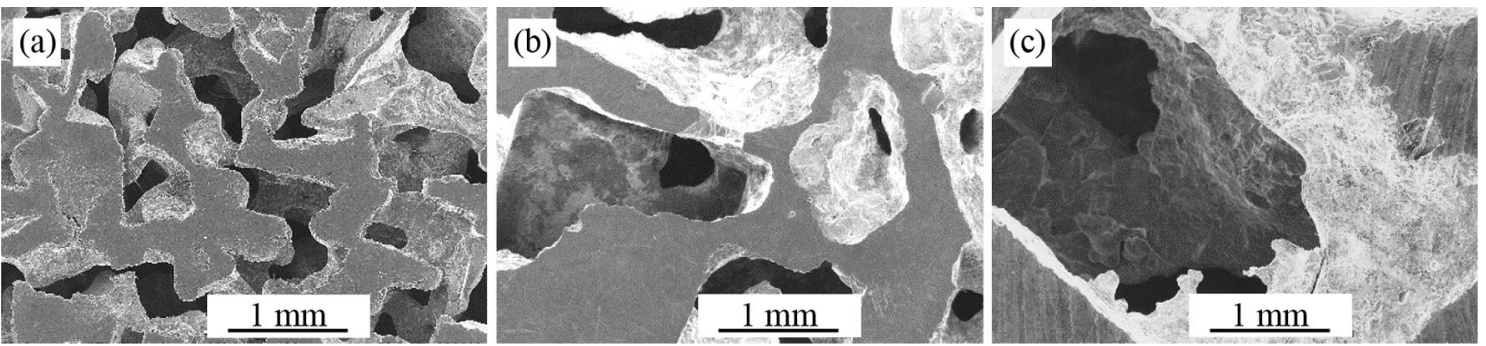

Figure 2: SEM micrographs of the Al foams produced, with pores (a) 0.71 to $1.00 \mathrm{~mm}$, (b) 2.00 to $2.38 \mathrm{~mm}$, and (c) 3.35 to $4.75 \mathrm{~mm}$.

TABLE 1: Physical properties of the produced Al foams.

\begin{tabular}{lcccccccc}
\hline \hline Pore size, $D_{P}(\mathrm{~mm})$ & $V_{\text {Al }}\left[\mathrm{cm}^{3}\right]$ & PPI & $\rho\left[\mathrm{g} \mathrm{cm}^{-3}\right]$ & $\rho^{*}$ & $\Phi$ & $\Phi_{\mathrm{S}}$ & $A_{\mathrm{M}}\left[\mathrm{mm}^{2}\right]$ & $D_{\mathrm{M}}[\mathrm{mm}]$ \\
\hline (A) $0.71-1.00$ & 21.76 & 29 & 1.04 & 0.38 & 0.62 & 0.37 & 0.52 & 0.81 \\
(B) $2.00-2.38$ & 21.44 & 12 & 1.02 & 0.38 & 0.62 & 0.58 & 3.63 & 2.15 \\
(C) $3.35-4.75$ & 21.52 & 7 & 1.03 & 0.38 & 0.62 & 0.55 & 11.38 & 3.81 \\
\hline \hline
\end{tabular}




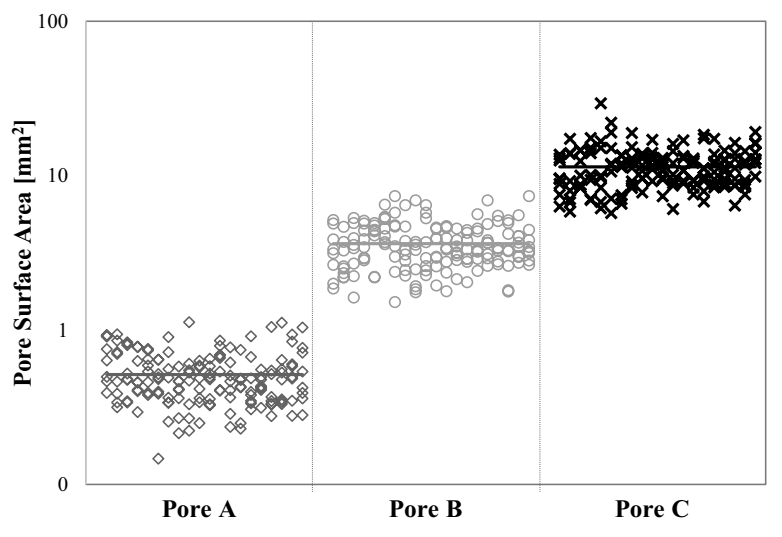

Figure 3: Quantitative analysis of pores' surface area, $A_{M}$.

variables, i.e., $\rho=1.02 \pm 0.01 \mathrm{~g} \mathrm{~cm}^{-3}, \rho^{\star}=0.38$ and $\Phi=0.62$. In contrast, PPI did present a clear correlation with pore size, having $29 \pm 2,12 \pm 1$ a,nd $7 \pm 1$, for pores $A, B$, and $C$, respectively. Bearing in mind that the pores were $\mathrm{NaCl}$ particles before leaching, this could be attributed to the more compacted packing of the smaller $\mathrm{NaCl}$ particles. Therefore, it is possible to produce foams with the same effective porosity, but different PPI.

Based on visual examination from Fig. 1, pores distribution throughout the foams is presumably homogeneous, despite its stochastic nature and the pores' shape irregularity. In this regard, pores distribution and dimensions, as well as porosity behavior through foams, were quantitatively assessed by means of image processing analysis. Superficial porosity, $\Phi_{S}$, through the foams was $0.37 \pm 0.02,0.58 \pm 0.02$, and $0.55 \pm 0.04$, for pores $A, B$, and $C$, respectively. Contrary to the occurred with effective porosity, where all samples presented similar values, superficial porosity decreased considerably for the smallest pore, while such variable was alike for the larger pore foams. This was attributed to the significant drop in the mean pore surface area, $A_{\mathrm{M}}$, of pores between 0.71 and $1.00 \mathrm{~mm}$, compared to that for pores between 2.00 and $2.38 \mathrm{~mm}$, and 3.35 and $4.75 \mathrm{~mm}$. The estimated mean pore surface area was $0.52 \pm 0.20$ $\mathrm{mm}^{2}, 3.63 \pm 1.22 \mathrm{~mm}^{2}$, and $11.38 \pm 3.49 \mathrm{~mm}^{2}$, for pores $A, B$, and $C$, respectively, as observed in Table 1 . However, superficial porosity remained within a reduced data dispersion through the foams, thereby demonstrating the homogeneous pores and porosity distribution.

All measurements taken to estimate mean pore surface area are shown in Fig. 3 (y-axis in logarithmic scale). From this figure, it can be appreciated that data dispersion is condensed around the average. Thereby, pores' surfaces are consistent despite their shape irregularity. Mean pore diameter, $D_{\mathrm{M}}$, was estimated assuming spherical geometries, resulting in 0.81 , 2.15 , and $3.81 \mathrm{~mm}$, for pores $A, B$, and $C$, respectively, which agrees well to the defined size intervals, i.e., 0.71 to $1.00,2.00$ to (a)

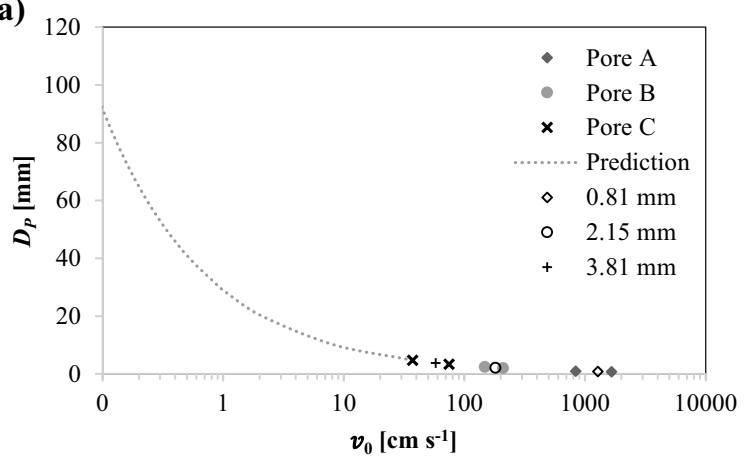

(b)

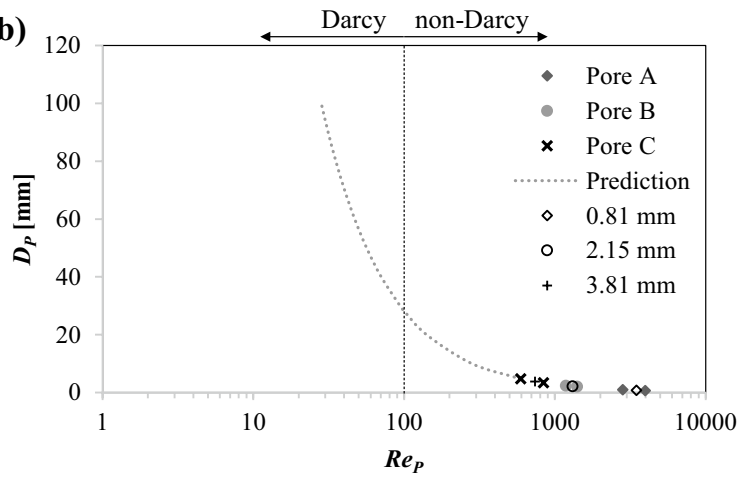

(c)

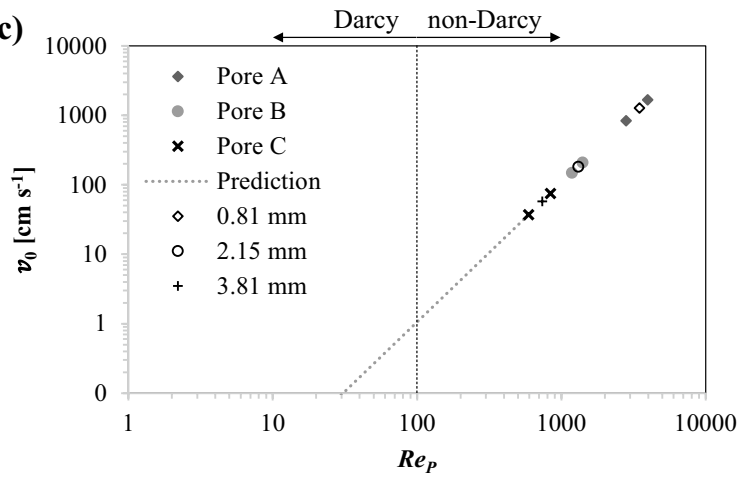

Figure 4: Flow behavior of the gasoline additive flowing through the foams (a) pores' diameter as a function of superficial velocity, (b) pores' diameter as a function of the modified Reynolds number for porous media, and (c) superficial velocity as a function of the modified Reynolds number for porous media.

$2.38 \mathrm{~mm}$, and 3.35 to $4.75 \mathrm{~mm}$. Thus, the obtained values of $D_{\mathrm{M}}$ could be considered as representatives.

\section{Flow behavior analysis}

The superficial velocity, $v_{0}$, was estimated according to $v_{0}=\frac{3 \Phi}{2 \pi r_{P}^{2}} Q$ [18], where $r_{P}$ refers to the pores' radius and $Q$ refers to the flowrate, assuming spherical pores and using data from Table 1. The modified Reynolds number for porous media, $R e_{P}$, was estimated according to $\operatorname{Re}_{P}=\frac{\rho_{f} D_{P} v}{\mu}$ [23], where $D_{P}$ refers 
to the pores' diameter, $\rho_{f}$ and $\mu$ refer to the density and dynamic viscosity of the gasoline additive at room temperature, experimentally determined as $0.78 \mathrm{~g} \mathrm{~cm}^{-3}$ and $23 \times 10^{-4} \mathrm{~Pa} \cdot \mathrm{s}$, respectively. It is worthy of mentioning that the dynamic viscosity at $200{ }^{\circ} \mathrm{C}$ was $\sim 24 \times 10^{-6} \mathrm{~Pa} \cdot \mathrm{s}$ (Fig. 4). Representative mean pore diameters were also plotted, being located between their corresponding size interval in all cases.

Figure 4a shows the pores' diameter as a function of the estimated superficial velocity ( $\mathrm{x}$-axis in logarithmic scale). In this figure, the inverse relationship between both variables can be appreciated. This behavior was attributed to the superficial velocity forced increment because of the conduction channels' reduction, to keep constant the preset flowrate. Figure $4 \mathrm{~b}$ shows the pores' diameter as a function of the estimated modified Reynolds number for porous media (x-axis in logarithmic scale). In this figure, it can be observed that, under the experimental conditions at room temperature, the flow through all tested foams falls within the non-Darcy regime, i.e., $R e_{P}>100$ $[24,25]$. Thus, the microscopic inertial forces and the force exerted by the foam's solid surface on the flowing fluid begin to be important, so that the energy dissipation turns out into the sum of the viscous forces and form drag [21,26]. Based on $v_{0}$ and $R e_{P}$, Darcy regime $\left(R e_{P}<100\right)$ would be achieved for foams with pores' diameter of at least $\sim 28.3 \mathrm{~mm}$, i.e., 7.4 times the mean pore diameter of $3.81 \mathrm{~mm}$, corresponding to
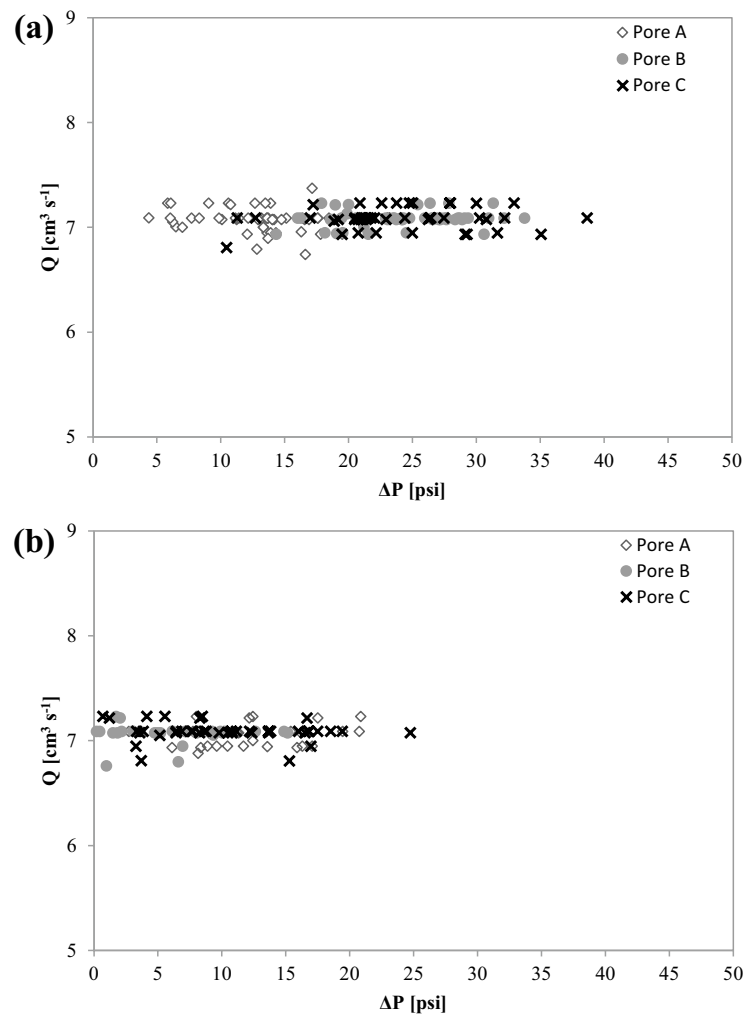

Figure 5: Drop of pressure as a function of flow rate at (a) room temperature and (b) $200^{\circ} \mathrm{C}$. the largest pore foams. On the other hand, at $200{ }^{\circ} \mathrm{C}$, Reynolds number would tend to increase due to the decrease of viscous forces due to applied temperature. Thus, flow behavior would get even more within the non-Darcy regime. Figure $4 \mathrm{c}$ shows the superficial velocity as a function of the modified Reynolds number for porous media (both $\mathrm{x}$ - and $\mathrm{y}$-axis in logarithmic scale), where it can be noticed that there is a positive correlation between these variables. Based on this figure, the critical superficial velocity for Darcy flow is $\sim 1.05 \mathrm{~cm} \mathrm{~s}^{-1}$. Furthermore, it was also observed that an increase in velocity necessary implies a significant increase in inertial forces, as $\operatorname{Re}_{P}$ depicts a rapid increment.

Figure 5 shows the drop of pressure, $\Delta P$, as a function of flowrate $\left(Q=7 \pm 0.2 \mathrm{~cm}^{3} \mathrm{~s}^{-1}\right)$ at room temperature (Fig. 5a) and $200{ }^{\circ} \mathrm{C}$ (Fig. 5b). Pressure losses associated to the confining wall effect were ignored, as all permeability-tested samples had the same dimensions [26]. As can be appreciated in this Fig. 5, $\Delta P$ was not constant; instead, it varied into a range of values. This drop of pressure behavior could be attributed to drag variations linked to the tortuosity and the bottlenecks interconnecting the pores, as well as the reached fluid velocity, as within the Forchheimer regime, the linearity between the fluid velocity and the pressure gradient disappears. It was initially thought that, at room temperature, the smallest pore foams were going to present higher pressure losses because of the friction and form drag resulting from their larger effective surface. Nevertheless, the pressure losses were the lowest for these foams when compared to the larger ones. Based on Fig. 4a, pore A foams would have lower flow resistance than pore $\mathrm{B}$ and $\mathrm{C}$ foams, as the flow pressure decreases as the superficial velocity increases.

On the other hand, at $200{ }^{\circ} \mathrm{C}$, the pressure losses presented lower values than those obtained at room temperature. It was initially hypothesized that pressure losses would tend to increase with an increment in testing temperature due to the conduction channels' reduction associated with the thermal expansion of aluminum, with this effect being more notorious for smaller pore sizes. Nevertheless, the drop of pressure behavior was alike for all studied samples despite pore size, contrary to expected results. The aforementioned suggest that the influence of dimensional parameters on the drop of pressure behavior becomes negligible at $200^{\circ} \mathrm{C}$. This was attributed to the low wettability of the gasoline additive with the sample's hot surface, resulting in reduced fluid retention. It is also plausible that the density of the testing fluid decreased at a higher temperature, therefore reducing the inertial forces and friction with the foam's surface.

\section{Structural performance assessment}

Considering the experimental conditions of pressure and temperature of the permeability tests and the friction between the 


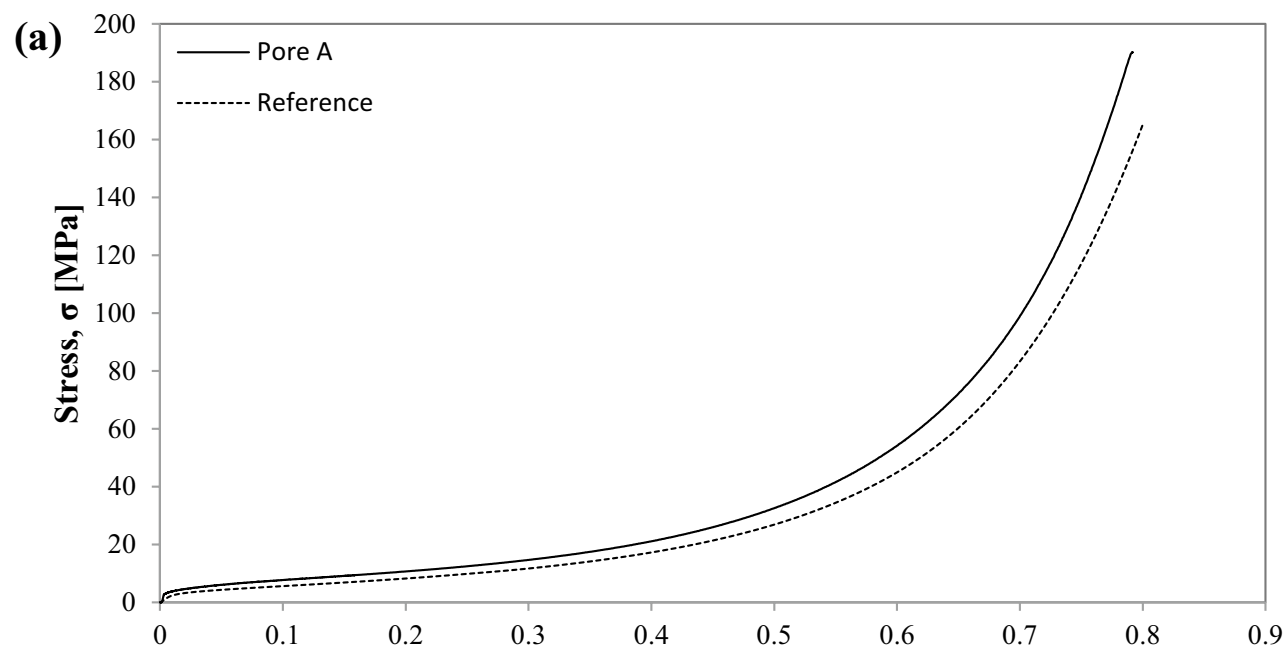

Strain, \&
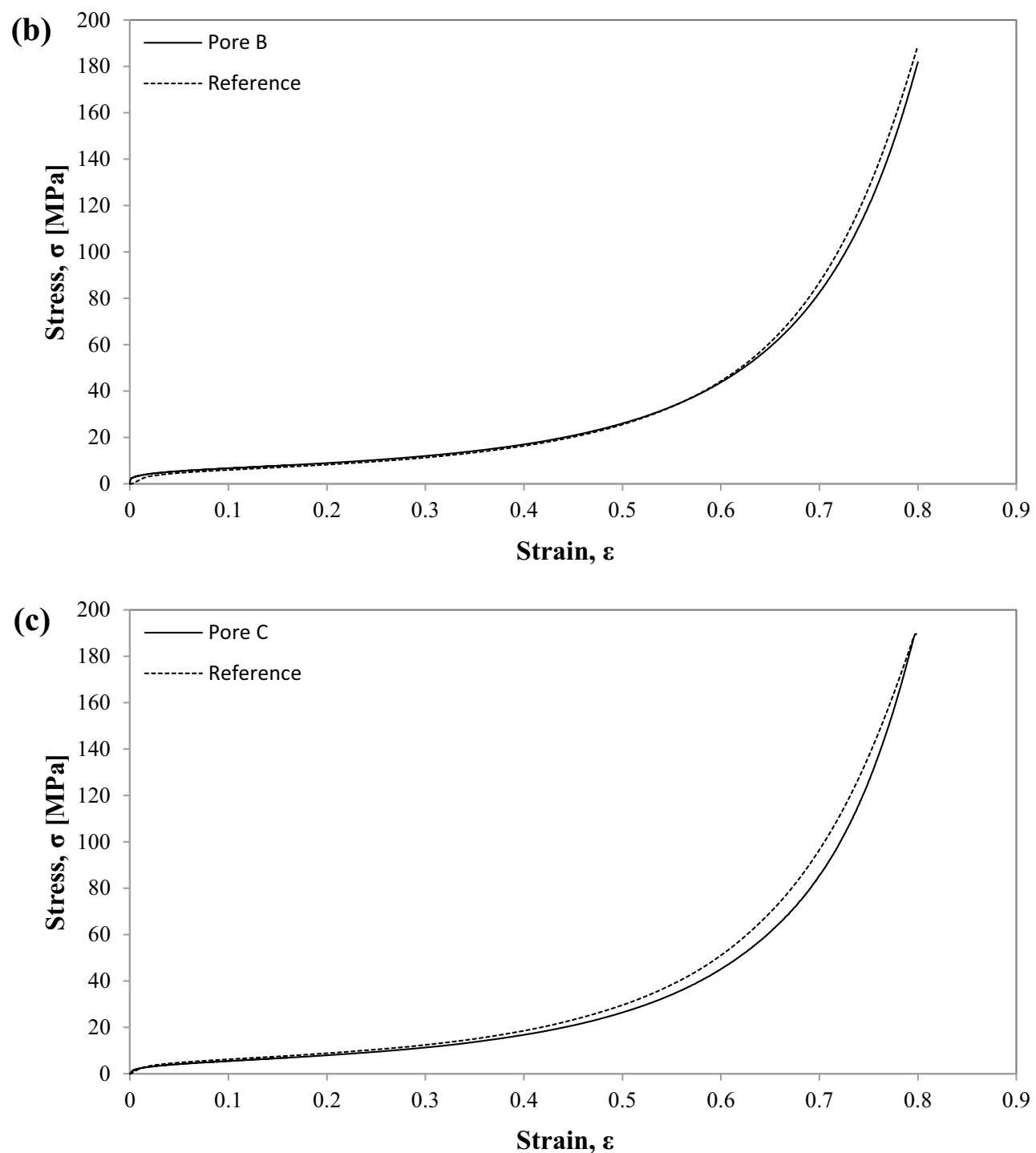

Figure 6: Stress-strain curves of the permeability-tested foams of pore (a) 0.71 to $1.00 \mathrm{~mm}$, (b) 2.00 to $2.38 \mathrm{~mm}$, and (c) 3.35 to $4.75 \mathrm{~mm}$. 
pressurized fluid and the surface of the sample, physical damage to the foams' structure would not be surprising. Therefore, the $200{ }^{\circ} \mathrm{C}$ permeability-tested foams were subjected to compression tests to generate their stress-strain curves, aiming to evaluate their structural integrity after the conduction of highly pressurized gasoline additive. Figure 6 shows the obtained stress-strain curves, with the sample reference without permeability test for each pore size. While the graph of the pore A foam (Fig. 6a) was above that of its reference, the graphs corresponding to pores $B$ (Fig. 6b) and C (Fig. 6c) were below the reference. However, in all cases, it was observed that the foams did not mechanically collapse, as the plotted curves exhibited the typical behavior of this material. This primarily suggests that the foams are potentially capable of supporting critical experimental conditions, as any possible structural damage would have caused an early collapse of the curves. Nevertheless, the creep of the aluminum matrix, resulting from exposure of the foams at $200{ }^{\circ} \mathrm{C}$, over prolonged periods, should be as well considered to affirm that open-cell Al foams are suitable material for the conduction of highly pressurized flow. Thus, a further investigation focused on this issue shall be done.

The energy absorption capacity, $W$, was calculated as the area under the curve, according to $W=\int_{0}^{\varepsilon} \sigma d \varepsilon$ [7], where $\sigma$ and $\varepsilon$ are the compressive stress and strain, respectively. The energy absorption capacity was calculated in the strain range from 0 to 0.5 , i.e., before the densification of the material. The energy absorbed was $7.13,5.86$, and $5.53 \mathrm{MJ} \mathrm{m}^{-3}$, for pore $A, B$, and $C$ foams, respectively, compared to $5.69,5.45$, and $6.13 \mathrm{MJ} \mathrm{m}^{-3}$ corresponding to the reference for each pore size. Thus, the toughness of the analyzed foams was not affected by the permeability tests. Young's modulus was taken as the slope of the linear elastic region in the curves, below 0.001 of strain. The plateau stress, $\sigma_{\mathrm{pl}}$, was calculated as the average of the stress values between the end of the linear elastic region and the beginning of the densification of the material, i.e., 0.001 and 0.5 of strain. The Young's modulus for the tested foams was between 1.75 to $1.85 \mathrm{GPa}$, while the plateau stress was between 7.5 and $10.1 \mathrm{MPa}$.

The Gibson-Ashby model [1] is widely used to predict the mechanical properties of foams as a function of their relative density, $\rho^{*}$, based on the bending as the essential deformation mechanism of cell walls. The model proposes simple relations between the relative density, Young's modulus, E, and plateau stress, $\sigma_{\mathrm{pl}}$. Young's modulus of foams is estimated according to $\frac{\mathrm{E}}{\mathrm{E}_{\mathrm{Al}}}=\mathrm{A}\left(\frac{\rho}{\rho_{\mathrm{Al}}}\right)^{2}$, where $\mathrm{E}_{\mathrm{Al}}$ is the Young's modulus of the metallic matrix (taken as $69 \mathrm{GPa}$ for aluminum) and $\mathrm{A}$ is a constant related to the cell geometry, usually taken as 1 . On the other hand, plateau stress of foams is estimated according to $\frac{\sigma_{p l}}{\sigma_{y s}}=\mathrm{C}\left(\frac{\rho}{\rho_{\mathrm{Al}}}\right)^{\frac{3}{2}}$, where $\sigma_{\mathrm{ys}}$ is the yield stress of the metallic matrix (35 $\mathrm{MPa}$ according to [27]) and $C$ is a constant related to the cell geometry. Data of polyurethane foams and many cellular metals suggest that $C=0.3$, although in practice, the value of the
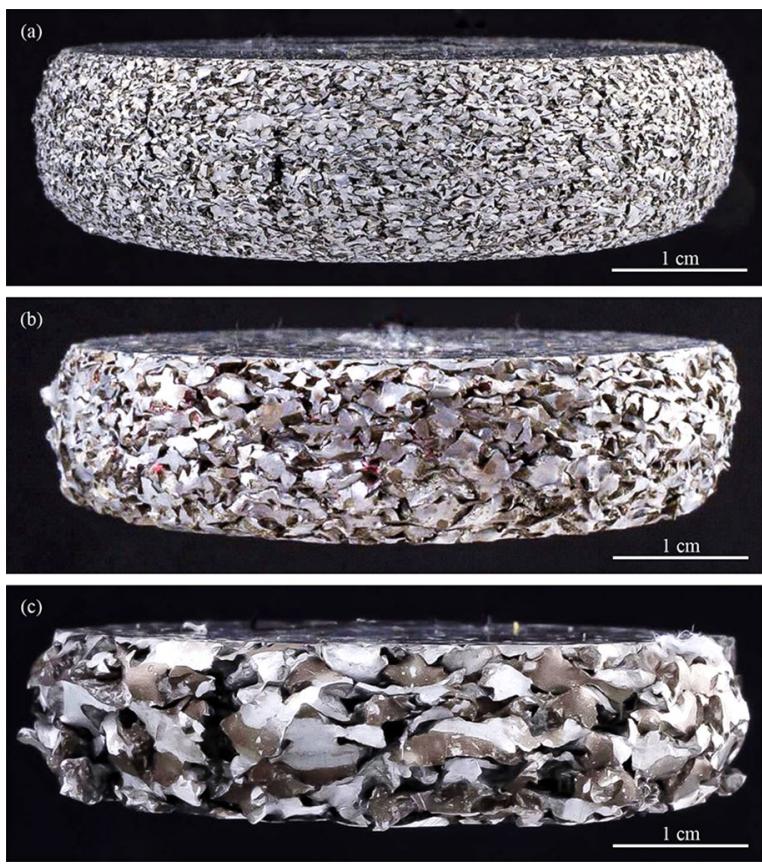

Figure 7: Permeability-tested open-cell Al foams after compression tests for pore (a), (b), and (c).

constants $A$ and $C$ vary over a wide range with different foam types. Taking $\rho^{\star}=0.38$ for all produced foams, the predicted values according to the Gibson-Ahsby model are $E=9.96 \mathrm{GPa}$ and $\sigma_{\mathrm{pl}}=2.46 \mathrm{MPa}$, which does not agree well with the experimental data, 1.75-1.85 GPa and 7.5-10.1 MPa, respectively. This could be attributed to the irregularity in terms of the shape of the pores, dispersed throughout the foams. As Gibson-Ashby's prediction assumes a simple cubic foam cell geometry, this model shows good fitting with honeycomb and periodic structures. For the foams studied in this work, an adjustment of the constants $A$ and $C$, related to the cell's geometry, would be necessary. However, similar outcomes are obtained for the foams employed as a reference in Fig. 6.

Figure 7 shows the front view of the permeability-tested foams after compression tests, at a deformation of $80 \%$ with regard to their original length. The deformation mechanism under the compressive load of metallic foams consists of the bending and subsequent fracture of their cell walls. Based on the metal or alloy that constitutes the metallic matrix, metallic foams can behave as a fragile or ductile material. In Fig. 7, it can be noted that the permeability-tested foams showed a ductile fracture, as the cell walls were plastically deformed without a catastrophic fracture. Although pore A (Fig. 7a) and B (Fig. 7b) foams presented such fracture, the ductile behavior of the material is more clearly appreciated on the pore C foam (Fig. 7c), with the cell walls completely bent.

In summary, the method presented in this work demonstrates that open-cell $\mathrm{Al}$ foams are capable of taking the fluid 
flow at critical conditions of pressure and temperature, without suffering substantial physical or structural damage, as all permeability-tested foams preserved their mechanical properties after the tests (Fig. 6), despite the pressure exerted by the fluid and the friction between the fluid flowing turbulently and the samples' surface. The aforementioned gives way to propose open-cell Al foams for functional applications that might require the conduction of highly pressurized flow, which could be of interest for the energy industry in the stabilized transportation of oil and gas products. Furthermore, this investigation lays the foundation for materials design and selection in fluid conduction applications, as the effect of pore size was studied in terms of flow and drop of pressure behaviors. Thereby, it could be possible to recommend larger pore foams for heat exchanging devices, as they had higher fluid retention due to the larger drop of pressure values (Fig. 5), while smaller pore foams would be better for fluids conduction in terms of energy efficiency, as their fluid retention was lower (Fig. 5) and their superficial velocity tends to increase as the pore size decreases (Fig. 4a).

\section{Conclusions}

The replication casting technique successfully produced Open-cell Al foams in three different pore sizes. All produced samples had similar porosity and relative density, despite the significant difference among pore size, attributing this to the shape irregularity of the $\mathrm{NaCl}$ used for their fabrication. Quantitative analysis of pores' dimensions and porosity through the foams was carried out through image processing. It was found that the total and mean surface area occupied by the pores is consistent in all foams, despite pores shape irregularity. The representative mean diameter of the pores was estimated at $0.81,2.15$, and $3.81 \mathrm{~mm}$, for pores $A$, $B$, and $C$, respectively, which agrees well with their defined size intervals. Drop of pressure behavior linked to the geometry of the conduction channels showed a correlation with the pore size when the permeability tests were carried out at room temperature. Nevertheless, such correlation disappeared at $200{ }^{\circ} \mathrm{C}$. This was attributed to the low wettability of the gasoline additive with the sample's hot surface. From compression tests, it was assessed the foams' structural capacity to conduct highly pressurized fluids at a temperature of up to $200^{\circ} \mathrm{C}$. The stress-strain curves generated from the permeability-tested specimens displayed the typical behavior of metallic foams under compressive load, finding that they presented similar mechanical properties than those observed in non-permeability-tested reference samples for each pore size. Creep of the aluminum matrix will be further considered in future investigations. Finally, the tested foams exhibited a ductile behavior under compressive load.

\section{Materials and methods}

\section{Foams fabrication}

The studied foams were manufactured by the replication casting technique $[5,7,8]$, using Al cylindrical ingots of commercial purity as load for infiltration and $\mathrm{NaCl}$ irregular particles as preform. The $\mathrm{NaCl}$ particles were sieved in three different pore sizes using meshes, to produce pores of (A) 0.71 to $1.00 \mathrm{~mm}$, (B) 2.00 to $2.38 \mathrm{~mm}$, and (C) 3.35 to $4.75 \mathrm{~mm}$, i.e., large, medium, and small pore size, aiming to find out the correlation between pore size and fluid flow behavior. An Al ingot of $6.2 \mathrm{~cm}$ in diameter and $8 \mathrm{~cm}$ in length was placed on top of $330 \mathrm{~g}$ of unsintered $\mathrm{NaCl}$ grains into a steel crucible. Then, the steel crucible was sealed and three times purged using Ar. Subsequently, the assembled crucible was placed into a resistance furnace at a working temperature of $780^{\circ} \mathrm{C}$, under an Ar atmosphere at a pressure of $0.5 \mathrm{~kg} \mathrm{~cm}^{-2}$ for $60 \mathrm{~min}$. Before melting the metal load at $780^{\circ} \mathrm{C}$, the $\mathrm{Al}$ cylindrical ingot acted as a piston, thereby sintering the $\mathrm{NaCl}$ particles at the atmospheric pressure and temperature conditions. Afterward, the solid $\mathrm{NaCl}$ was infiltrated with the molten $\mathrm{Al}$ by increasing the Ar pressure for $30 \mathrm{~min}$ at pressures of $2,1.65$, and $1.25 \mathrm{~kg} \mathrm{~cm}^{-2}$ for pores $A, B$, and $C$, respectively. Finally, the crucible was extracted from the furnace and the composite material $\mathrm{Al}-\mathrm{NaCl}$ was retired from and machined into cylinders of $5 \mathrm{~cm}$ in length and $3.81 \mathrm{~cm}$ in diameter, according to testing cell dimensions. The $\mathrm{NaCl}$ perform was leached in distilled water by means of an ultrasonic shower, remaining only the $\mathrm{Al}$ foam.

\section{Physical characterization}

All produced specimens were physically characterized. The pores per inch, PPI, were determined as the number of pores in one linear inch. The density, $\rho$, of each sample was estimated from measurements of its volume and weight. The relative density, $\rho^{\star}$, was determined as the ratio between the foam's density and the bulk density of the $\mathrm{Al}\left(\rho / \rho_{\mathrm{Al}}\right)$. The effective foams porosity, $\Phi$, was obtained according to $\Phi=\frac{V_{\mathrm{S}}-V_{\mathrm{Al}}}{V_{\mathrm{S}}}$, where $V_{\mathrm{S}}$ is the volume of the sample $\left(57 \mathrm{~cm}^{3}\right)$ and $V_{\mathrm{Al}}$ is the volume occupied by the $\mathrm{Al}$ (solid volume) measured using a He pycnometer (Quantachrome Ultrapyc 1200e). Quantitative porosity analysis through the foams was carried out, starting off from foam samples sectioned in eight cylindrical slices for each pore condition. Superficial porosity, $\Phi_{S}$, taken as the fraction area occupied by the pores, was measured for each slice. On the other hand, mean pore surface area, $A_{\mathrm{M}}$, was estimated as the average of aleatory measurements of the surface area occupied by one single pore, using the commercial software Image J. Twenty aleatory measurements were taken per slice, i.e., 160 measurements per pore size. The foams' slices are shown in Figs. S-1 to S-3 


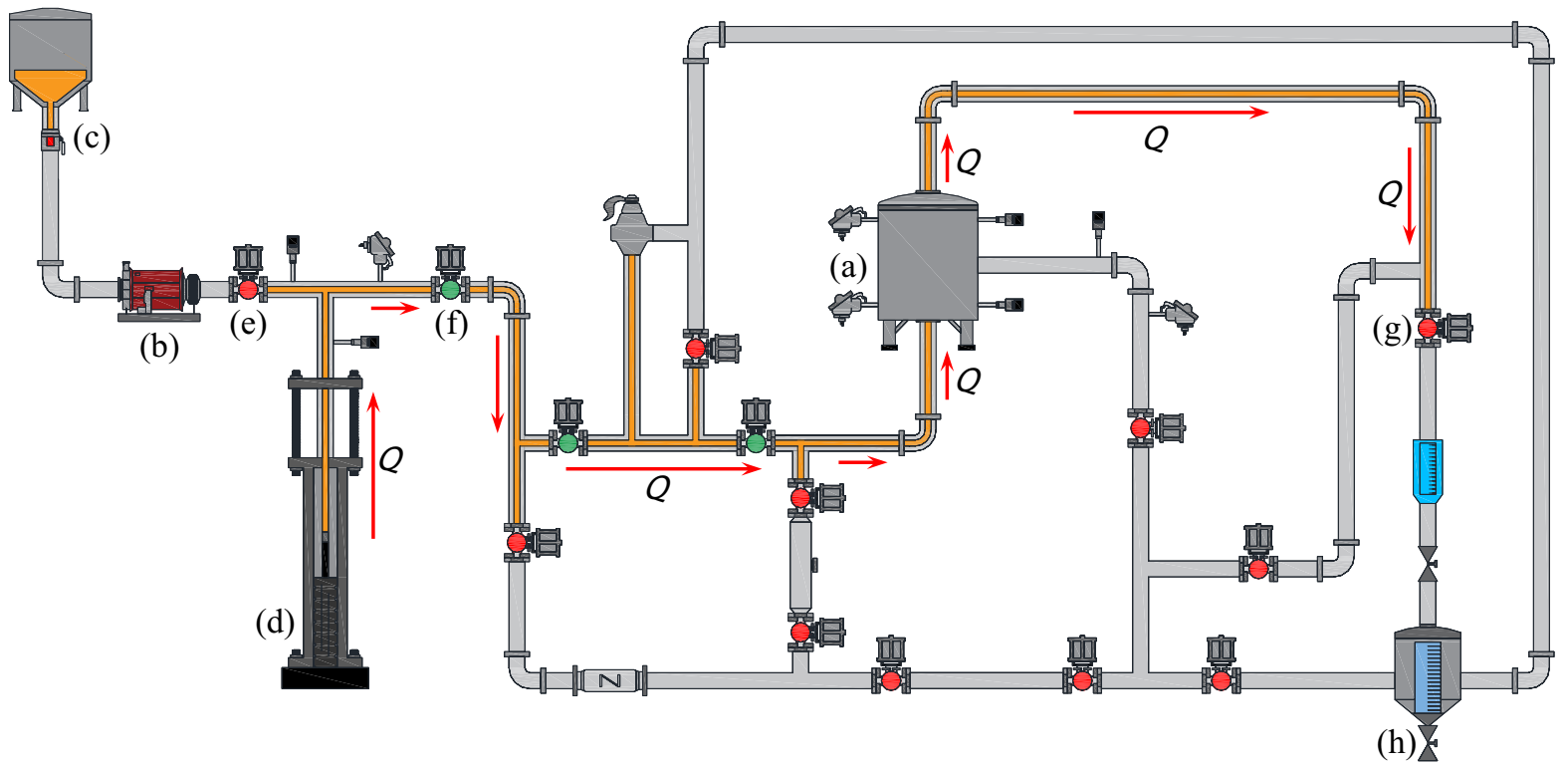

Figure 8: Diagram of the pore-permeameter: (a) testing cell, (b) mechanical pump, (c) storage tank, (d) hydraulic press, (e-g) valves, and (h) exhaust tank.

(e)

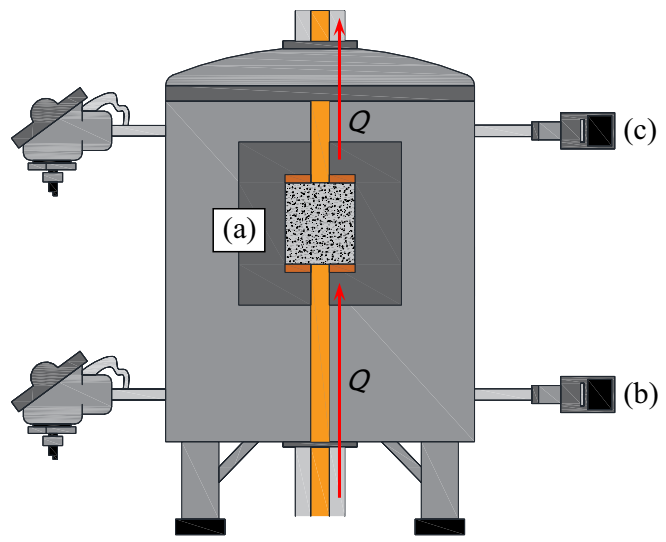

Figure 9: Diagram of the testing cell: (a) testing section, $(b, c)$ pressure gauges, and $(d, e)$ resistance temperature detectors.

(see Electronic Supplementary Material), for pores $A, B$ and $C$, respectively. Mean pore diameter, $D_{\mathrm{M}}$, was estimated assuming spherical geometries.

\section{Permeability tests and structural integrity assessment}

Permeability tests were conducted using a pore-permeameter and gasoline additive as testing fluid. Considering that this investigation aims to propose open-cell $\mathrm{Al}$ foams for possible applications in oil/gas extraction and conduction, gasoline additive was used due to its physical properties (density, $\rho$, and dynamic viscosity, $\mu$ ), similar to those for crude oil [28]. The pore-permeameter setup is sketched in Fig. 8. Firstly, the foam sample is mounted into the testing cell (Fig. 8a). Permeability test initiates with the mechanical pump (Fig. 8b) moving the gasoline additive from the storage tank (Fig. 8c) toward the hydraulic press (Fig. 8d). Once the latter is full, its valve closes (Fig. 8e). Subsequently, while the testing cell valve is open (Fig. 8f), and the exhaust tank valve is closed (Fig. 8g), the hydraulic press injects the gasoline additive toward the testing cell, at preset increasing pressure intervals achieving values of up to 25,000 psi. Once the highest value of the preset pressure interval is reached, the exhaust tank valve is opened, and the fluid is ejected from the system (Fig. 8h). The testing cell setup is sketched in Fig. 9. Prior to each test, the foam sample is mounted into the testing section (Fig. 9a), using two Teflon/ copper gaskets on the bottom and top to properly seal the cell and guarantee sample confinement. The pressure at the inlet and outlet of the sample was measured each second with two pressure gauges located at the entrance (Fig. 9b) and exit (Fig. 9c) of the testing section. The testing section temperature was measured with two resistance temperature detectors, located at the entrance (Fig. 9d) and exit (Fig. 9e). All permeability tests were conducted at a flowrate, $Q$, of $7 \mathrm{~cm}^{3} \mathrm{~s}^{-1}$.

Dynamic viscosity, $\mu$, of gasoline additive was measured at room temperature and $200{ }^{\circ} \mathrm{C}$, using a parallel plate rheometer, at shear rates ranging from 10 to $1500 \mathrm{~s}^{-1}$. Compression tests were carried out using a universal mechanical testing machine Instron $1125-5500 \mathrm{R}$, at a strain rate of $4.1 \times 10^{-4} \mathrm{~s}^{-1}$, to generate the stress-strain curves of the permeability-tested samples in order to determine their mechanical properties, i.e., energy absorption capacity, W, Young's Modulus, E, and plateau stress, $\sigma_{\mathrm{pl}}$. 


\section{Acknowledgments}

The authors would like to acknowledge the financial support from DGAPA-PAPIIT UNAM “IN102422" for funding the project. C. Flores, G. A. Lara-Rodriguez, A. Tejeda, O. Novelo-Peralta, C. Ramos, R. Reyes, A. Lopez V., F. Garcia, E. de la Calleja, V. Aranda, E. Hernandez-Mecinas, A. Bobadilla, and C. Carrillo are also acknowledged for their technical support. "Por mi raza hablará el espíritu”.

\section{Data availability}

The datasets generated during the current study are available in the following link: https://drive.google.com/drive/folde rs/1s4AJ7qT6WxbML9fEY20RQcgKw79xsN6P?usp=sharing.

\section{Declarations}

Conflict of interest The authors declare that they have no known competing financial interests or personal relationships that could have appeared to influence the work reported in this paper.

\section{Supplementary Information}

The online version contains supplementary material available at https://doi.org/10.1557/s43578-021-00382-4.

\section{Open Access}

This article is licensed under a Creative Commons Attribution 4.0 International License, which permits use, sharing, adaptation, distribution and reproduction in any medium or format, as long as you give appropriate credit to the original author(s) and the source, provide a link to the Creative Commons licence, and indicate if changes were made. The images or other third party material in this article are included in the article's Creative Commons licence, unless indicated otherwise in a credit line to the material. If material is not included in the article's Creative Commons licence and your intended use is not permitted by statutory regulation or exceeds the permitted use, you will need to obtain permission directly from the copyright holder. To view a copy of this licence, visit http://creativecommons.org/ licenses/by/4.0/.

\section{References}

1. L.J. Gibson, M.F. Ashby, Cellular Solids: Structure and Properties, 2nd edn. (Cambridge University Press, Cambridge, 1997), pp. $1-51$

2. P.S. Liu, G.F. Chen, Porous Materials: Processing and Applications, 1st edn. (Butterworth-Heinemann, Waltham, 2014), pp. 1-188

3. F. García-Moreno, Materials (2016). https://doi.org/10.3390/ ma9020085
4. J. Banhart, JOM (2000). https://doi.org/10.1007/ s11837-000-0062-8

5. E.M. Elizondo-Luna, F. Barari, R. Woolley, R. Goodall, J. Visualized Exp. (2014). https://doi.org/10.3791/52268

6. J.F. Despois, A. Marmottant, L. Salvo, A. Mortensen, Mater. Sci. Eng. A (2007). https://doi.org/10.1016/j.msea.2006.03.157

7. J.O. Osorio-Hernandez, M.A. Suarez, R. Goodall, G.A. LaraRodriguez, I. Alfonso, I.A. Figueroa, Mater. Des. (2014). https:// doi.org/10.1016/j.matdes.2014.07.015

8. J. Trinidad, I. Marco, G. Arruebarrena, J. Wendt, D. Letzig, E. Sáenz, R. Goodall, Adv. Eng. Mater. (2014). https://doi.org/10. 1002/adem.201300236

9. T. Shi, X. Chen, Y. Cheng, Y. Li, Mater. Trans. (2017). https://doi. org/10.2320/matertrans.M2016244

10. M.A. Suarez, I.A. Figueroa, G. Gonzalez, G.A. Lara-Rodriguez, O. Novelo-Peralta, J. Alloys Compd. (2014). https://doi.org/10. 1016/j.jallcom.2013.08.015

11. M.F. Besser, T. Eisenhammer, MRS Bull. (1997). https://doi.org/ 10.1557/S088376940003445X

12. J.M. Dubois, Chem. Soc. Rev. (2012). https://doi.org/10.1039/ $\mathrm{c} 2 \mathrm{cs} 35110 \mathrm{~b}$

13. T. Wan, Y. Liu, C. Zhou, X. Chen, Y. Li, J. Mater. Sci. Technol. (2021). https://doi.org/10.1016/j.jmst.2020.05.039

14. A. Sutygina, U. Betke, M. Scheffler, Adv. Eng. Mater. (2020). https://doi.org/10.1002/adem.201901194

15. J. Bin, W. Zejun, Z. Naiqin, Scr. Mater. (2007). https://doi.org/10. 1016/j.scriptamat.2006.08.070

16. J. Banhart, Prog. Mater. Sci. (2001). https://doi.org/10.1016/ S0079-6425(00)00002-5

17. K. Boomsma, D. Poulikakos, J. Fluids Eng. (2002). https://doi. org/10.1115/1.1429637

18. J.F. Despois, A. Mortensen, Acta Mater. (2005). https://doi.org/ 10.1016/j.actamat.2004.11.031

19 P. Fernandez-Morales, C.A. Cano-Montoya, J.A. Perez-Meza, M.A. Navacerrada, Ing. Univ. (2017). https://doi.org/10.11144/ Javeriana.iyu21-1.tppm

20. N. Dukhan, J. Fluids Eng. (2012). https://doi.org/10.1115/1. 4005678

21. A.J. Otaru, H.P. Morvan, A.R. Kennedy, Acta Mater. (2018), https://doi.org/10.1016/j.actamat.2018.02.051

22. S. Mancin, C. Zilio, A. Cavallini, L. Rossetto, Int. J. Heat Mass Transfer (2010). https://doi.org/10.1016/j.ijheatmasstransfer. 2010.03.015

23. Z. Zeng, R. Crigg, Transp. Porous Media (2006). https://doi.org/ $10.1007 / \mathrm{s} 11242-005-2720-3$

24. T.H. Chilton, A.P. Colburn, Ind. Eng. Chem. (1931). https://doi. org/10.1021/ie50260a016

25. E.F. Blick, F. Civan, SPE Reservoir Eng. (1988). https://doi.org/ 10.2118/16202-PA 
26. N. Dukhan, M. Ali, Transp. Porous Media (2012). https://doi. org/10.1007/s11242-011-9841-7

27 J.G. Kaufman, Introduction to Aluminum Alloys and Tempers, 1st Printing (ASM International, Materials Park, 2000), pp. 39-76
28 Q. Zhang, L. Zuo, C. Wu, C. Sun, X. Zhu, Colloids Surf. A (2021). https://doi.org/10.1016/j.colsurfa.2020.125562 